\title{
Preparation of an acellular spinal cord scaffold to improve its biological properties
}

\author{
HUI XING ${ }^{1}$, HONG YIN ${ }^{1}$, CHAO SUN $^{1}$, XIANJUN REN ${ }^{1}$, YONGYANG TIAN ${ }^{2}$, MIAO YU ${ }^{1}$ and TAO JIANG ${ }^{1}$ \\ ${ }^{1}$ Department of Orthopedics, Xinqiao Hospital, Army Medical University, Chongqing 400037; \\ ${ }^{2}$ Emergency Department of University-Town Hospital of Chongqing Medical University, Chongqing 401331, P.R. China
}

Received September 29, 2018; Accepted April 30, 2019

DOI: $10.3892 / \mathrm{mmr} .2019 .10364$

\begin{abstract}
In recent years, acellular spinal cord scaffolds have been extensively studied in tissue engineering. Notably, acellular spinal cord scaffolds may be used to treat spinal cord injury; however, the method of preparation can result in low efficiency and may affect the biological properties of cells. This study aimed to use EDC crosslinking, combined with chemical extraction for tissue decellularization, in order to improve the efficiency of acellular scaffolds. To make the improved stent available for the clinical treatment of spinal cord injury, it is necessary to study its immunogenicity. Therefore, this study also focused on the adherence of rat bone marrow mesenchymal stem cells to scaffolds, and their differentiation into neuron-like cells in the presence of suitable trophic factors. The results revealed that EDC crosslinking combined with chemical extraction methods may significantly improve the efficiency of acellular scaffolds, and may also confer better biological characteristics, including improved immunogenicity. Notably, it was able to promote adhesion of rat bone marrow mesenchymal stem cells and their differentiation into neuron-like cells. These results suggested that the improved preparation method may be promising for the construction of multifunctional acellular scaffolds for the treatment of spinal cord injury.
\end{abstract}

\section{Introduction}

In recent years, acellular matrix scaffolds have shown great potential in animal studies (1). Decellularized tissue grafts have been used to promote regeneration of certain systems, including the skin (2), liver (3), bone (4), heart (5), ovaries (6), cartilage (7) and peripheral nerves (8); however, few studies

Correspondence to: Dr Tao Jiang, Department of Orthopedics, Xinqiao Hospital, Army Medical University, 183 Xinqiao Street, Chongqing 400037, P.R. China

E-mail: fromcq2000@sina.com

Key words: acellular spinal cord scaffolds, EDC crosslinking, efficiency, immunogenicity, rat bone marrow mesenchymal stem cells, trophic factor, cell differentiation have attempted to explore their potential in central nervous system repair (9). Our previous studies used a chemical extraction method, involving Triton X-100 and sodium deoxycholate, to successfully prepare acellular scaffolds $(10,11)$. The prepared acellular spinal cord scaffold has a three-dimensional structure and excellent biocompatibility; however, the chemical extraction method used to achieve complete decellularization was unstable in early experiments. Notably, this method is capable of inducing complete decellularization; however, it has a low efficiency. Therefore, in order to improve decellularization and efficiency, the preparation of acellular spinal cord stents must be improved.

Stem cells are an alternative source of functional nerve cells (12). Growing evidence has suggested that stem cells can differentiate into neuron-like cells in the appropriate microenvironment and when stimulated by nerve growth factors $(13,14)$. Rat bone marrow mesenchymal stem cells (BMSCs) are a type of adult stem cell; these cells are suitable for cell therapy, due to their availability, rapid proliferation, pluripotency, successful integration and innate tolerance in the host tissue (15). In addition, it has been reported that BMSCs, under stimulation by the nourishing factors neurotrophin-3 (NT-3), basic fibroblast growth factor (bFGF) and epidermal growth factor (EGF), may differentiate into neuronal cells, as verified by neuron-specific antibodies (14). However, the method by which BMSCs differentiate into neuronal cells only be assessed in a limited way in the two dimensions of cell culture plates, and how to successfully cultivate acellular spinal cord stents requires further investigation.

The present study hypothesized that 3D acellular scaffolds derived from the rat spinal cord may provide a simulated natural spinal microenvironment that facilitates the differentiation of BMSCs into neuron-like cells in vitro. Furthermore, compared with in the traditional stent group, the benefits of the improved EDC crosslinking scaffold on BMSC adhesion and differentiation were investigated. Furthermore, in this study, an improved dynamic culture system with added trophic factors was used to control the environmental conditions. Reverse transcription-quantitative PCR (RT-qPCR) and immunostaining were used to determine MSC differentiation into neuron-like cells. In addition, scaffolds were surgically inserted into a rat model to study their immunogenicity. 


\section{Materials and methods}

Scaffold preparation and experimental groups. Adult male $\mathrm{SD}$ rats, 50 days old, were purchased from the animal center of Daping Hospital affiliated Army Medical University ( $\mathrm{n}=30$; weight, $\sim 250 \mathrm{~g}$ ). The rats were housed at a temperature of $25 \pm 1^{\circ} \mathrm{C}$ with a $12 \mathrm{~h} \mathrm{light} / \mathrm{dark}$ cycle, and access to food and water was ad libitum. In the normal group, rats were administered pentobarbital sodium ( $45 \mathrm{mg} / \mathrm{kg}$ body weight) via intraperitoneal injection, after which $\sim 20 \mathrm{~mm}$ of the thoracic spinal cord was obtained from each animal. Spinal cord samples were immersed in PBS $(0.01 \mathrm{~mol} / \mathrm{l})$, washed clean of blood and then stored at $-70^{\circ} \mathrm{C}$.

The traditional stent group was generated according to a method previously described by Guo et al (10). Thoracic spinal cords were harvested in the same manner as for the normal group. After gradient thawing $\left(-70,-20\right.$ and $\left.4^{\circ} \mathrm{C}\right)$ the spinal cords were rinsed twice in a desktop thermostat oscillator $\left(25^{\circ} \mathrm{C}\right.$; $100 \mathrm{rpm} 1 \mathrm{~h} / \mathrm{wash}$ ) in PBS. Subsequently, PBS was replaced with $1 \%$ Triton X-100 (Sigma-Aldrich; Merck KGaA) solution. The spinal cords were rinsed for $3 \mathrm{~h}$ at $25^{\circ} \mathrm{C}$ with agitation, and were then rinsed again with washing solution $(0.01 \%$ PBS) three times $(1 \mathrm{~h} /$ rinse). The solution was then replaced with $1 \%$ sodium deoxycholate solution (Sigma-Aldrich; Merck KGaA) for $3 \mathrm{~h}$ at $25^{\circ} \mathrm{C}$ with agitation. After this, the spinal cords were rinsed with washing solution with agitation at $25^{\circ} \mathrm{C}$ three times $(1 \mathrm{~h} /$ rinse). The nerve segments were again agitated in $1 \%$ Triton X-100 and 1\% sodium deoxycholate solution. Finally, the segments were washed a further three times at $25^{\circ} \mathrm{C}$ with agitation ( $1 \mathrm{~h} / \mathrm{wash})$ in a $0.01 \% \mathrm{PBS}$ solution. The tissue segments were finally stored at $-20^{\circ} \mathrm{C}$.

In the improved stents group, the following steps were conducted: i) The thoracic spinal cord samples were extracted according to the aforementioned method, and were immediately placed in $1.5 \mathrm{ml}$ microcentrifuge tubes. ii) The tubes were then placed in liquid nitrogen for $2 \mathrm{~min}$ and placed in a water bath at $42^{\circ} \mathrm{C}$ for $8 \mathrm{~min}$; ultra-pure water was added for $50 \mathrm{~min}$ and replaced every $25 \mathrm{~min}$. iii) The ultra-pure water was removed and $1 \%$ Triton $\mathrm{X}-100$ was added to the samples and incubated for $12 \mathrm{~h}$ at $25^{\circ} \mathrm{C}$; iv) ultra-pure water was then added again for $30 \mathrm{~min}$ and incubated at $25^{\circ} \mathrm{C}$, the water was replaced every $10 \mathrm{~min}$ prior to being discarded. v) $1 \%$ sodium deoxycholate was added and incubated for $12 \mathrm{~h}$ at $25^{\circ} \mathrm{C}$, and vi) ultra-pure water was added for $30 \mathrm{~min}$ and incubated at $25^{\circ} \mathrm{C}$, the water was replaced every $10 \mathrm{~min}$. vii) EDC liquid (EDC:NHS, 5:2; $0.01 \mathrm{~mol} / \mathrm{l} \mathrm{PBS,} 0.5 \mathrm{~g}$ EDC and $0.2 \mathrm{~g}$ NHS; Sigma-Aldrich; Merck KGaA) was added to the samples at room temperature for $10 \mathrm{~h}$. Finally, steps iii)-iv) were repeated in a desktop thermostat oscillator (100 rpm) and all acellular spinal cord stents were stored at $-20^{\circ} \mathrm{C}$.

Gross morphology. The scaffolds obtained from all three groups were observed and assessed for normal morphology, color, texture and stiffness.

Hematoxylin and eosin $(H \& E)$ staining. Scaffolds from the three groups ( $\mathrm{n}=20 /$ group) were fixed with $4 \%$ paraformaldehyde (Beyotime Institute of Biotechnology) for $1 \mathrm{~h}$ at $25^{\circ} \mathrm{C}$, dehydrated and frozen; these sections then underwent $\mathrm{H} \& \mathrm{E}$ staining. Residual cells and external matrix retention was observed under an optical microscope (magnification, x50 and $\mathrm{x} 400$ ). Cell residue evaluation criteria were as follows: No residue or little debris, grade I; 1-5 residual cells, grade II; 5-10 residual cells, grade III; $>10$ residual cells, grade IV.

DAPI staining. Randomly selected normal spinal cord samples and grade I scaffolds were placed in a 24 -well plate, and treated as follows: i) To each well, $2 \mathrm{ml} 4 \%$ paraformaldehyde was added and the scaffolds were fixed at room temperature for $30 \mathrm{~min}$; ii) paraformaldehyde was then removed and $2 \mathrm{ml} 0.01 \mathrm{~mol} / \mathrm{l} \mathrm{PBS}$ was added to a 24 well plate with agitation, which was rinsed for $5 \mathrm{~min}$, the PBS was discarded, and the process repeated. iii) Subsequently, $5 \mu \mathrm{g} / \mathrm{ml}$ DAPI (Sigma-Aldrich; Merck KGaA) was added to each well, the plate was covered and incubated in the dark for $5 \mathrm{~min}$ at room temperature; iv) DAPI was discarded and $2 \mathrm{ml} 0.01 \mathrm{~mol} / \mathrm{l}$ PBS was added to each well with slight agitation, after which the plate was rinsed for $10 \mathrm{~min}$; this step was repeated until no more dye could be removed. Cell residue was observed in random fields of view using a Leica laser confocal microscope (Leica Microsystems $\mathrm{GmbH}$ ) and a normal light microscope. The present study verified whether there was cell residue inside the scaffold.

Detection of residual DNA content. A total of 10 scaffolds $(300 \mu \mathrm{g})$ were selected from each of the three groups, and were sorted after mixing and grinding using a glass homogenizer; $\sim 1 / 10$ of the mixture was used to detect DNA, according to the manufacturer's protocol (HiPure Tissue DNA Mini kit; cat. no. D3121-02; Guangzhou Meiji Biotechnology Co., Ltd.). Briefly, the samples underwent the following steps: i) Digestion and cleavage, and ii) column purification. The DNA samples from the three groups were then subjected to DNA analysis using a spectrophotometer (ND-2000C; NanoDrop Technologies; Thermo Fisher Scientific, Inc.), according to the manufacturer's protocol. The scaffolds underwent DNA extraction a further two times to obtain another two batches of DNA; each batch of DNA was assessed three times to obtain the mean, which was then used for statistical analysis.

Scanning electron microscopy (SEM) analysis of the scaffold ultrastructure. Scaffolds from the three groups were fixed in glutaraldehyde $(20 \mathrm{~g} / \mathrm{l})$ at $4^{\circ} \mathrm{C}$ for $1 \mathrm{~h}$ and the surface was exposed to the following steps: Dehydration in graded ethanol series (30, 50, 70, 90, 95 and $100 \%$ each for $10 \mathrm{~min})$; critical point drying and spray-gold treatment. Images of the 3D ultrastructure of the scaffolds were captured by SEM (Hitachi,Ltd.).

Scaffold immunogenicity analysis in vivo. Bilateral surgery was conducted on 24 rats as follows: Anesthesia was induced via an intraperitoneal injection of sodium pentobarbital $(30 \mathrm{mg} / \mathrm{kg}$ ). At the surgical incision site on the back, the skin was shaved and disinfected with iodophor solution, after which, a $10-\mathrm{mm}$ skin incision was made. A cavity was made via blunt dissection. Scaffolds from the traditional and improved groups were then implanted into the skin incision. Wounds were sutured using cotton. At 1, 2, 3 and 4 weeks, tissues around the stent that exhibited inflammation, and the residual stent, were surgically obtained; the penetration of $\mathrm{CD} 4^{+}$cells into the grafts was analyzed by immunohistochemistry. Tissues 
were prepared from $5 \mu \mathrm{m}$ frozen sections, were fixed with $4 \%$ paraformaldehyde for $15 \mathrm{~min}$ at $25^{\circ} \mathrm{C}$ and $0.25 \%$ Triton was used to permeabilize cells $(10 \mathrm{~min})$. Cells were washed twice with PBST and blocked with $3 \% \mathrm{H}_{2} \mathrm{O}_{2}\left(25^{\circ} \mathrm{C}\right.$ for $\left.30 \mathrm{~min}\right)$. Antibodies used were as follows: CD4 monoclonal antibody (1:200; cat. no. YM3070; ImmunoWay Biotechnology Company) and a goat anti-mouse IgG horseradish peroxidase polymer secondary antibody (1:500; cat. no. PV6002; OriGene Technologies, Inc.). Images were captured using an Olympus light microscope (x400).

Culture of BMSCs with additional trophic factors. A BMSC strain (RASMX-01001) was purchased directly from Cyagen US, Inc. and cultured at $37^{\circ} \mathrm{C}$ in DMEM/F12 (HyClone; GE Healthcare Life Sciences) containing $10 \%$ fetal bovine serum (FBS; Gibco; Thermo Fisher Scientific, Inc.) and $0.2 \%$ ascorbic acid in an incubator containing $5 \% \mathrm{CO}_{2}$; the medium was changed every 3 days. Cells were digested with $0.25 \%$ trypsin (HyClone; GE Healthcare Life Sciences). Subsequently, the slides were pre-embedded in polylysine (cat. no. P6407; Sigma-Aldrich; Merck KGaA) and laminin (cat. no. L6274; Sigma-Aldrich; Merck KGaA), placed in 24-well plates and cell culture medium was added. A passage 5 MSC cell suspension was then added to the 24 -well plate at a concentration of $2 \times 10^{5}$. The medium was replaced once cells reached $80 \%$ confluence. The experimental group was cultured in $3 \mathrm{ml}$ low-glucose DMEM (HyClone; GE Healthcare Life Sciences) + 10 ng/ml NT-3 (cat. no. 450-3; Peprotech, Inc.) + 10 ng/ml bFGF (cat. no. 400-29; Peprotech, Inc.) + 10 ng/ml EGF (cat. no. AF-400-25; Peprotech, Inc.) + 2\% FBS (Gibco; Thermo Fisher Scientific, Inc.) + 1\% penicillin-streptomycin (HyClone; GE Healthcare Life Sciences) + 1\% N2 (Gibco; Thermo Fisher Scientific, Inc.) + 1\% glutamine (HyClone; GE Healthcare Life Sciences). The control group was cultured with $3 \mathrm{ml}$ low-glucose $\mathrm{DMEM}+2 \% \mathrm{FBS}+1 \%$ penicillin-streptomycin $+1 \% \mathrm{~N} 2+1 \%$ glutamine. All groups were cultured for 7 days.

BMSC adherence to scaffolds. The traditional and improved groups of acellular spinal cord scaffolds are referred to as the traditional group and improved group, respectively. Briefly, in the traditional and improved groups, four scaffolds were analyzed. The stents were trimmed to $1 \mathrm{~cm}$, and incubated in PBS solution for $48 \mathrm{~h}$ at $4^{\circ} \mathrm{C}$ to remove residual chemicals. Subsequently, the stents were freeze-dried and stored in a sealed microcentrifuge tube, prior to undergoing ${ }^{60} \mathrm{Co}$ irradiation disinfection (dose, $16 \mathrm{~Gy}$ ) for sterilization; the stents were then stored at $-20^{\circ} \mathrm{C}$. Passage $3 \mathrm{BMSCs}$ were selected for this analysis and were adjusted to a cell density to $3.7 \times 10^{5} / \mathrm{ml}$. Subsequently, sterilized stents were placed in 24-well plates, and a micro-sampler was used to inject $40 \mu \mathrm{l}$ cell suspension into the interior and also onto the surface, after which, $50 \mu \mathrm{l}$ complete medium [DMEM/F12 (HyClone; GE Healthcare Life Sciences) + 10\% FBS (Gibco; Thermo Fisher Scientific, Inc.) $+1 \%$ penicillin-streptomycin] was added and incubated at $37^{\circ} \mathrm{C}$ for $4 \mathrm{~h}$. Stents were then rinsed with PBS three times, and fixed in $2 \mathrm{ml} 4 \%$ paraformaldehyde at room temperature for $30 \mathrm{~min}$. Subsequently, the paraformaldehyde was discarded and the stents were rinsed with PBS for a further three times. DAPI $(500 \mu \mathrm{l})$ was then added to each well for staining and the samples were incubated in the dark for $5 \mathrm{~min}$, before being rinsed a further three times with PBS. Finally, a laser confocal microscope (Leica Microsystems $\mathrm{GmbH}$ ) was used to evaluate DAPI staining and absorption. Each cell composite scaffold was imaged in three random fields, and the average number of cells per field was calculated.

Cell growth in scaffolds. The traditional and improved groups were evaluated for cell differentiation (16). Briefly, stents were pre-sterilized with $16 \mathrm{~Gy}{ }^{60} \mathrm{Co}$ irradiation. The slides were pre-incubated with lysine (Sigma-Aldrich; Merck KGaA) and laminin (Sigma-Aldrich; Merck KGaA), and placed into a 24-well plate; the scaffolds were cut and flattened suitably and were bonded with the cell slide via tissue adhesion (cat. no. LOT215503N1; B.BRAUN AG). In addition, equal weight scaffolds were adhered to a 6-well plate without the cell slide, using the aforementioned method; the combination of scaffolds and plates were pretreated with DMEM/F12 for $30 \mathrm{~min}$ prior to seeding the scaffolds with cells. For the 24-well plates, a $3 \mu \mathrm{l}$ $4 \times 10^{5}$ BMSC suspension was added directly to each well; for the 6-well plates, a $20 \mu 14 \times 10^{5}$ cell suspension was seeded into each well. To promote cell adhesion, the plates were incubated for $2 \mathrm{~h}$ at $37^{\circ} \mathrm{C}$ in a humidified atmosphere containing $5 \% \mathrm{CO}_{2}$, then $0.4 \mathrm{ml} \mathrm{DMEM} / \mathrm{F} 12+10 \% \mathrm{FBS}$ was added to each well of the 24-well plate, and $3 \mathrm{ml}$ each well of the 6-well plate. Plates were incubated for $72 \mathrm{~h}$, prior to the addition of $0.4 \mathrm{ml}$ neurogenic induction medium (DMEM/low glucose $+2 \%$ FBS $+1 \% 10 \mathrm{ml} / \mathrm{ml} \mathrm{NT}-3+\mathrm{bFGF}+\mathrm{EGF}$ ) to each well of the 24-well plates, and $3 \mathrm{ml}$ to each well of the 6 -well plates; the plates were incubated at $37^{\circ} \mathrm{C}$ for 7 days. The 24-well plates were used for immunofluorescence. Cells grown in 6-well plates were digested, washed and filtered, and then subjected to RT-qPCR analysis.

Cell differentiation in scaffolds. Cell differentiation in the scaffolds of the two groups was analyzed by confocal microscopy. Briefly, cell-seeded scaffolds (according to the aforementioned procedure) were washed with PBS and fixed in $3.7 \%$ formaldehyde at $25^{\circ} \mathrm{C}$ for $20 \mathrm{~min}$. Subsequently, they were immersed in $0.1 \%$ Triton X-100 for 3 min and washed again in PBS. The samples were stained overnight with a primary antibody against Neurofilament heavy (Nefh; 1:50; cat. no. ab82259; Abcam) at $4^{\circ} \mathrm{C}$. Excess primary antibody was removed and the scaffolds were washed three times in PBS, then incubated with an Andy Fluor $^{\mathrm{TM}} 488$ goat anti-mouse $\mathrm{IgG}(\mathrm{H}+\mathrm{L})$ antibody $(1: 100$; cat. no. L109A; GeneCopoeia, Inc.) at room temperature for $4 \mathrm{~h}$. In addition, cell nuclei were labeled with $20 \mathrm{mg} / \mathrm{ml}$ DAPI in the dark for $5 \mathrm{~min}$. Imaging experiments were performed under laser confocal microscopy (Leica TCS SP5; Leica Microsystems $\mathrm{GmbH}$ ). Integrated Performance Primitives software (Intel Corporation) was used to select the fluorescent region around each cell; five cells were randomly selected from each image. The grayscale value was obtained by calculating the brightness ratio of the area, which was done automatically using the software. Average grayscale values were obtained for each image. Each group had three average grayscale values and these were plotted as a graph using GraphPad Prism 5.01 (GraphPad Software, Inc.).

$R T-q P C R$ analysis of cell differentiation. Cells grown in 6 -well plates from the two groups were washed and RNA was extracted using RNAzol (GeneCopoeia, Inc.). According to the manufacturer's protocol, an All-In-One ${ }^{\mathrm{TM}}$ First-Strand 


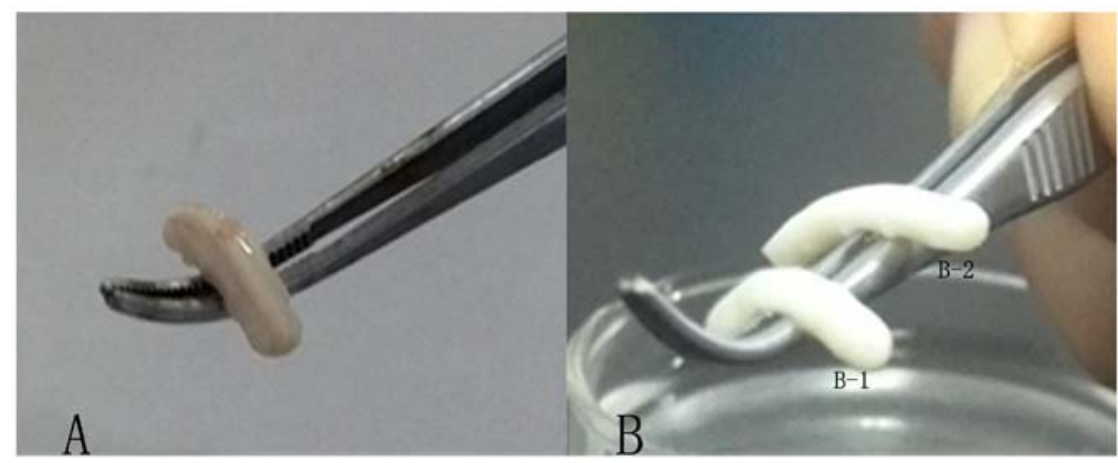

Figure 1. General morphology of the three groups. (A) Normal spinal cord. (B-1) Traditional and (B-2) improved group stents.

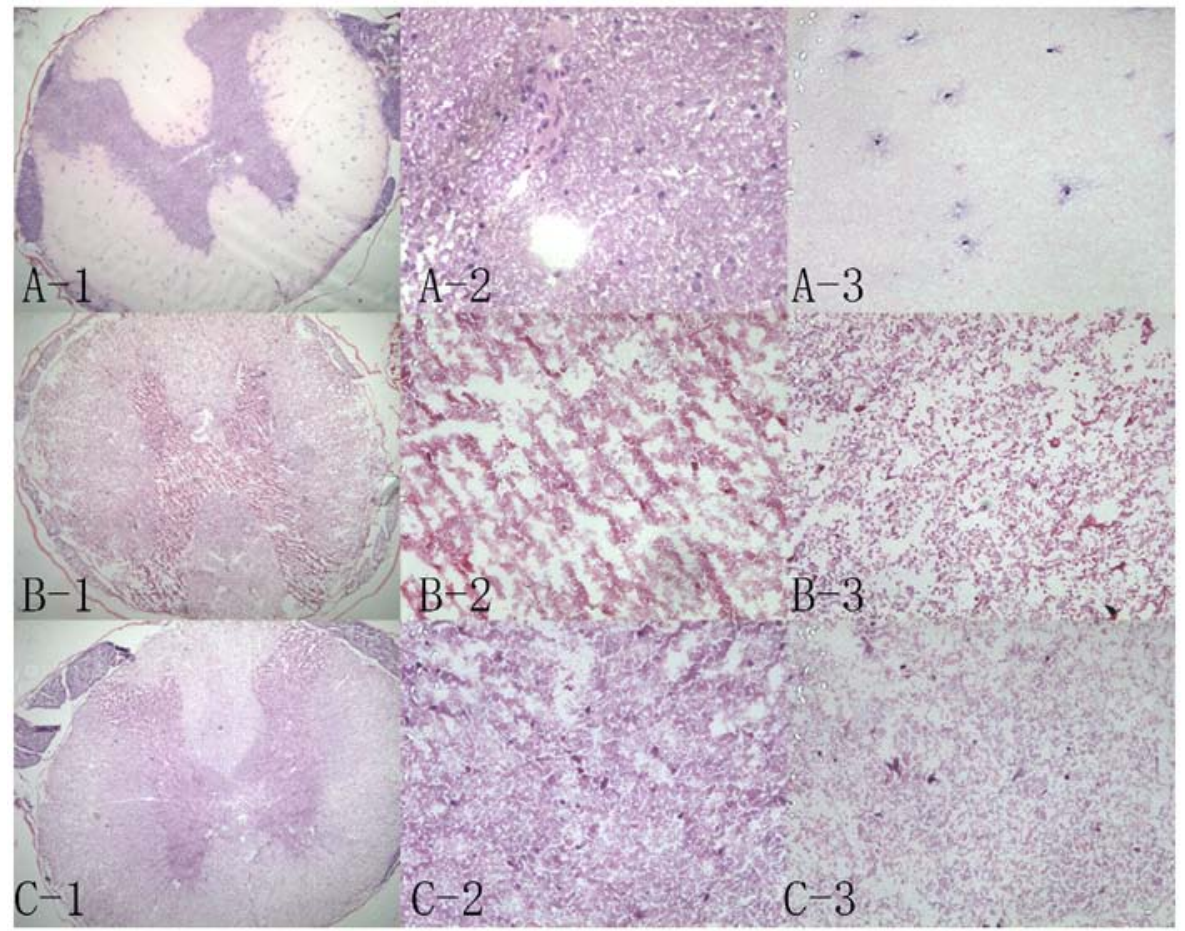

Figure 2. Hematoxylin and eosin staining in the three groups. (A-1) Normal spinal cord (magnification, $\mathrm{x} 50$ ); (A-2) gray matter in the normal spinal cord (magnification, x400); (A-3) white matter in the normal spinal cord (magnification, x400). (B-1) Improved scaffolds (magnification, x50); (B-2) gray matter in the improved scaffolds (magnification, x400); (B-3) white matter in the improved scaffolds (magnification, x400). (C-1) Traditional scaffolds (magnification, $\mathrm{x} 50$ ); (C-2) gray matter in the traditional scaffolds (magnification, $\mathrm{x} 400$ ); (C-3) white matter in the traditional scaffolds (magnification, $\mathrm{x} 400$ ).

cDNA Synthesis kit (cat. no. AORT-0020; GeneCopoeia, Inc.) was used for RT. Briefly, $1 \mu \mathrm{g}$ total RNA was used for DNA synthesis. qPCR was performed as follows: Initial denaturation at $95^{\circ} \mathrm{C}$ for $10 \mathrm{~min}$; followed by 40 cycles at $95^{\circ} \mathrm{C}$ for $10 \mathrm{sec}, 60^{\circ} \mathrm{C}$ for $20 \mathrm{sec}$ and $72^{\circ} \mathrm{C}$ for $34 \mathrm{sec}$ using an ViiA 7 Dx RT-PCR system (Applied Biosystems; Thermo Fisher Scientific, Inc.). The mRNA expression levels of GAPDH were used as an internal control. Changes in expression were determined using the $2^{-\Delta \Delta \mathrm{Cq}}$ method (17). The primer sequences used included: Nefh ( $2 \mu \mathrm{M}$; cat. no. RQP048942; GeneCopoeia, Inc.) and GAPDH ( $2 \mu \mathrm{M}$; cat. no. HQP006940; GeneCopoeia, Inc.).

Statistical analysis. Data are expressed as the mean \pm standard deviation. SPSS version 19 software (IBM Corp.) was used to analyze the data. Comparisons among multiple groups were performed using one-way ANOVA followed by Tukey's post hoc test. Comparisons between two groups were performed using independent t-test. Comparisons between two categorical variables were performed using $\chi^{2}$ test. $\mathrm{P}<0.05$ was considered to indicate a statistically significant difference.

\section{Results}

General morphology. The morphology of the three groups was cylindrical, milky white, with a certain degree of stiffness. Compared with the stiffness of the normal spinal cord (Fig. 1A), the traditional (Fig. 1B-1) and improved groups (Fig. 1B-2) appeared weaker. However, the improved group (Fig. 1B-2) appeared slightly stronger than the traditional group (Fig. 1B-1). 
Table I. Cell residue evaluation by hematoxylin and eosin staining.

\begin{tabular}{lccccc}
\hline Group & Grade I & Grade II & Grade III & Grade IV & Grade I+II rate (\%) \\
\hline Traditional & 1 & 1 & 0 & 18 & 10 \\
Improved & 16 & 3 & 0 & 1 & $95^{\mathrm{a}}$ \\
\hline
\end{tabular}

${ }^{\text {ap }}<0.05$ vs. the traditional group, $\chi^{2}$ test.
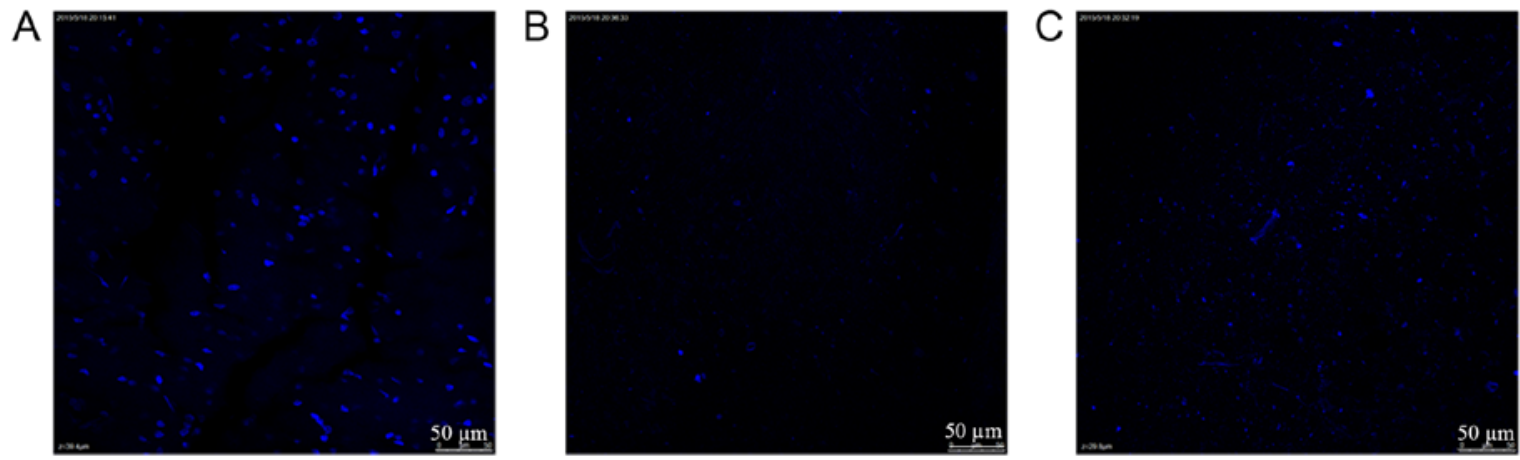

Figure 3. DAPI staining. (A) Normal spinal cord; (B) grade I scaffolds from the improved group; (C) grade I scaffolds from the traditional group.

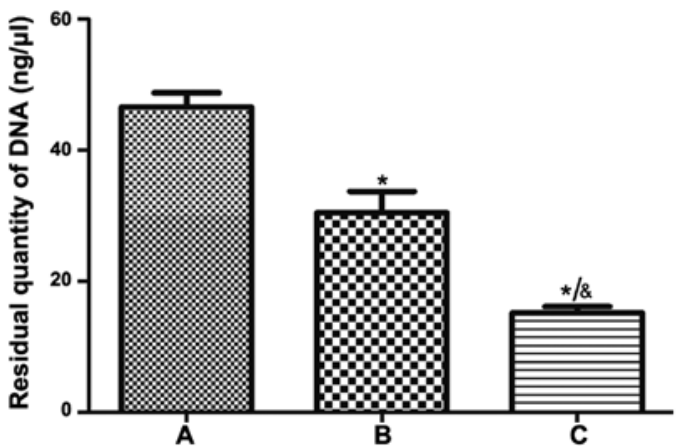

Figure 4.DNA residue in the three groups. (A) Normal spinal cord; (B) traditional group; (C) improved group. Data are presented as the mean \pm standard deviation, $\mathrm{n}=3$. ${ }^{*} \mathrm{P}<0.05$ compared with group $\mathrm{A},{ }^{\text {\& }} \mathrm{P}<0.05$ compared with group $\mathrm{B}$, one-way ANOVA was followed by Tukey's post hoc test.

Histological analysis. Results of H\&E staining demonstrated that the tissue structure of the normal spinal cord was compact (Fig. 2A-1); there were numerous neuronal cells in the gray matter (Fig. 2A-2) and fewer neuronal cells in the white matter (Fig.2A-3). The traditional group exhibited a few cells in the local region (Fig. 2C-1-3), particularly in the central area (Fig. 2C-2). Conversely, the white matter was completely decellularized (Fig. 2C-3). The improved group (Fig. 2B-1-3) demonstrated superior decellularization in the central area (Fig. 2B-2). For the two groups, 20 samples were randomly selected. Using $\mathrm{H} \& \mathrm{E}$ scoring, the residual cells in the cross-sections from all scaffolds were analyzed. In the majority of improved scaffolds, there were $\leq 5$ residual cells, including in the gray and white matter; $\sim 95 \%$ of scaffolds were grade I+II. Conversely, in the majority of traditional scaffolds, there were $>10$ residual cells; only $10 \%$ of scaffolds were grade I+II (Table I). There was a significant difference between the number of grade I+II scaffolds in the traditional and improved groups $(\mathrm{P}<0.05)$.
DAPI staining. For laser confocal microscopy, many intact cells were present and observed in the normal spinal cord (Fig. 3A). For the grade I scaffolds of the traditional and improved groups (Fig. 3B and C), the internal layers exhibited few whole and broken residual cells. Notably, for the grade I stents in the traditional and improved groups, DAPI estimates were in accordance with those from H\&E staining. The EDC crosslinking method appeared to efficiently decellularize stents.

DNA residue. After normal spinal cord tissue was treated by different acellular methods, the DNA residue in the improved group was less than that in the traditional group (Fig. 4); the decellularization method was more efficient in the improved group than in the traditional group.

Electron microscopy. A tight 3D network and a complete extracellular matrix was observed in normal spinal cord tissue (Fig. 5A). With regards to 3D structure, the improved group (Fig. 5B) exhibited a markedly tighter network than the traditional group (Fig. 5C). Furthermore, the gross appearance of the improved group was slightly more complete than that of the traditional group.

Immunogenicity analysis. Lymphocytes, neutrophils and fibroblasts were detected in the two groups in vivo. After 2 weeks of implantation, cell infiltration in the improved group (Fig. 6A) was markedly weaker than in the traditional group (Fig. 6B). After 4 weeks, cell infiltration in the improved (Fig. 6C) and traditional groups (Fig. 6D) was gradually decreased; however, the reduction in the improved group was more obvious.

BMSC differentiation. After 7 days of culture, normal BMSCs (Fig. 7A) were adherent and had grown closely with a regular pattern, and a long fusiform or triangular shape. Following the addition of neurotrophic factors, BMSCs differentiated into 

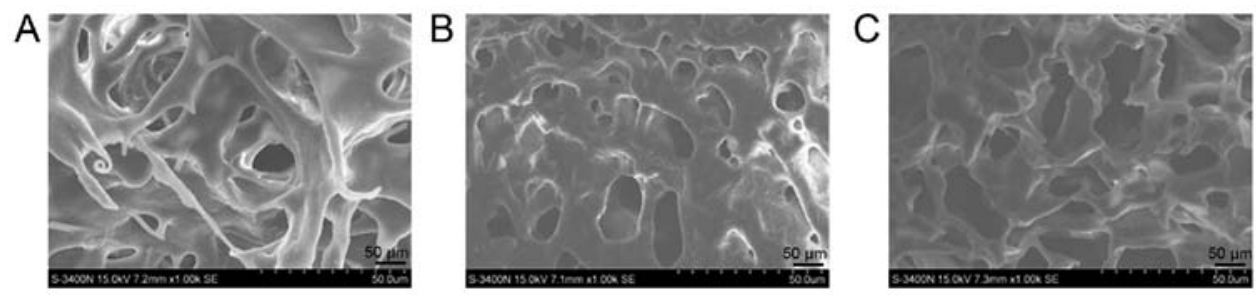

Figure 5. Electron microscopy of the three groups to observe the three-dimensional network. (A) Normal spinal cord; (B) traditional group and (C) improved group.
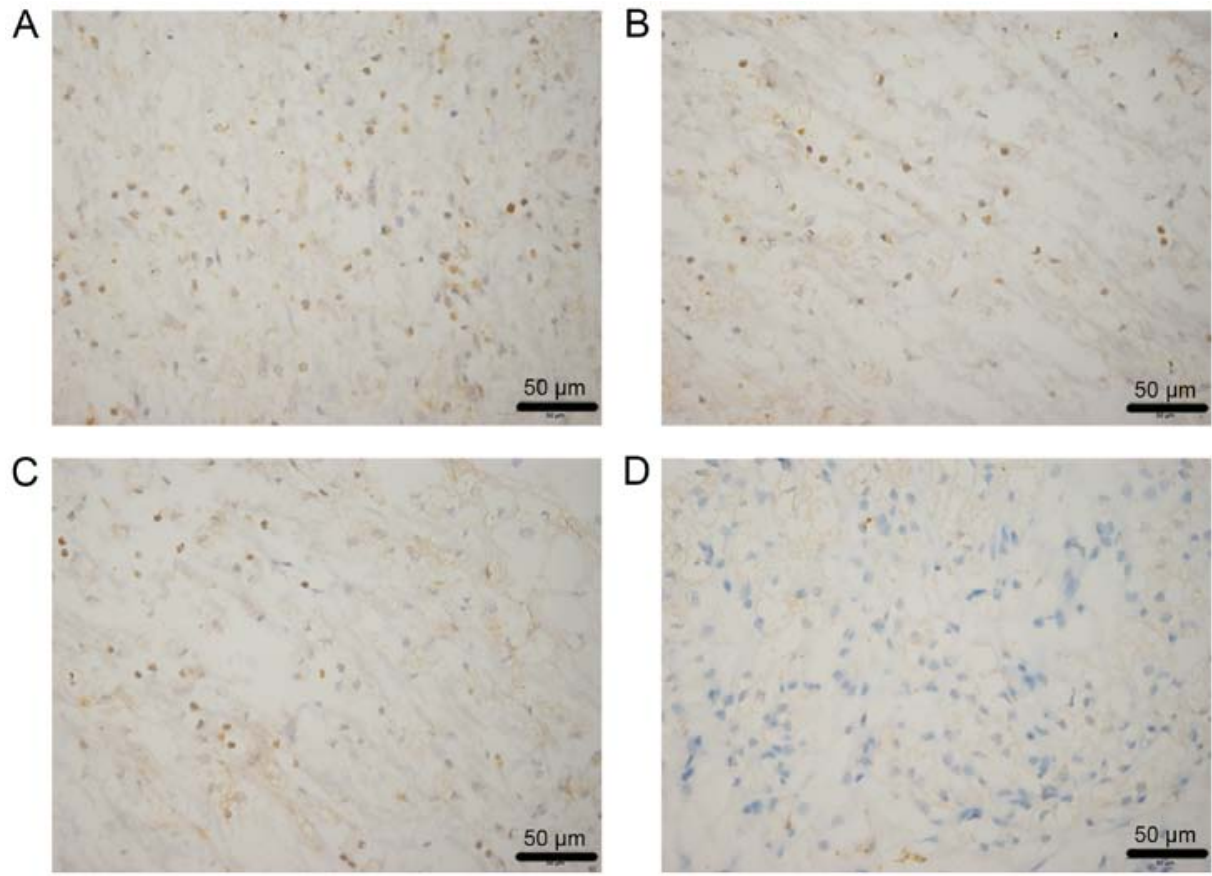

Figure 6. Immunogenicity analysis of two groups at different time points. (A) Traditional group after 2 weeks, (B) improved group after 2 weeks, (C) traditional group after 4 weeks and (D) improved group after 4 weeks. Brown, CD4+; blue, DAPI.
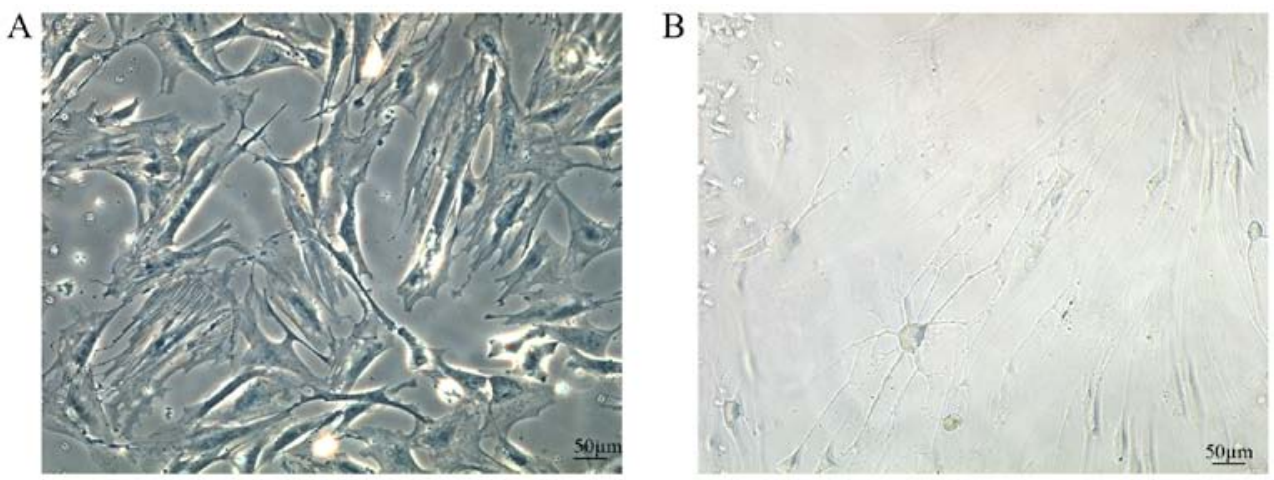

Figure 7. BMSC differentiation in vitro following the addition of neurotrophic factors. (A) Normal BMSC morphology and (B) morphology of neuron-like cells. BMSC, bone marrow mesenchymal stem cell.

neuron-like cells. Notably, the nuclei had lost their original fusiform shape, and the cells formed axon-like structures and became interconnected (Fig. 7B).

BMSC adhesion. After $4 \mathrm{~h}$ of culture, DAPI staining revealed that the two groups exhibited nuclear fluorescence on the adhesive scaffolds (Fig. 8A and B). Furthermore, the number of adherent cells in the improved group scaffolds (Fig. 8A) was greater than in the traditional group scaffolds (Fig. 8B). The control group, with no BMSCs added to the stents, exhibited no spotty nuclear fluorescence (Fig. 8C and D). Cell adhesion to scaffolds was significantly increased in the improved group compared with in the traditional group $(\mathrm{P}<0.05$, Fig. $8 \mathrm{E})$.

BMSC differentiation. After 7 days of culture, MSCs could grow on the surface of the traditional and improved scaffolds. 

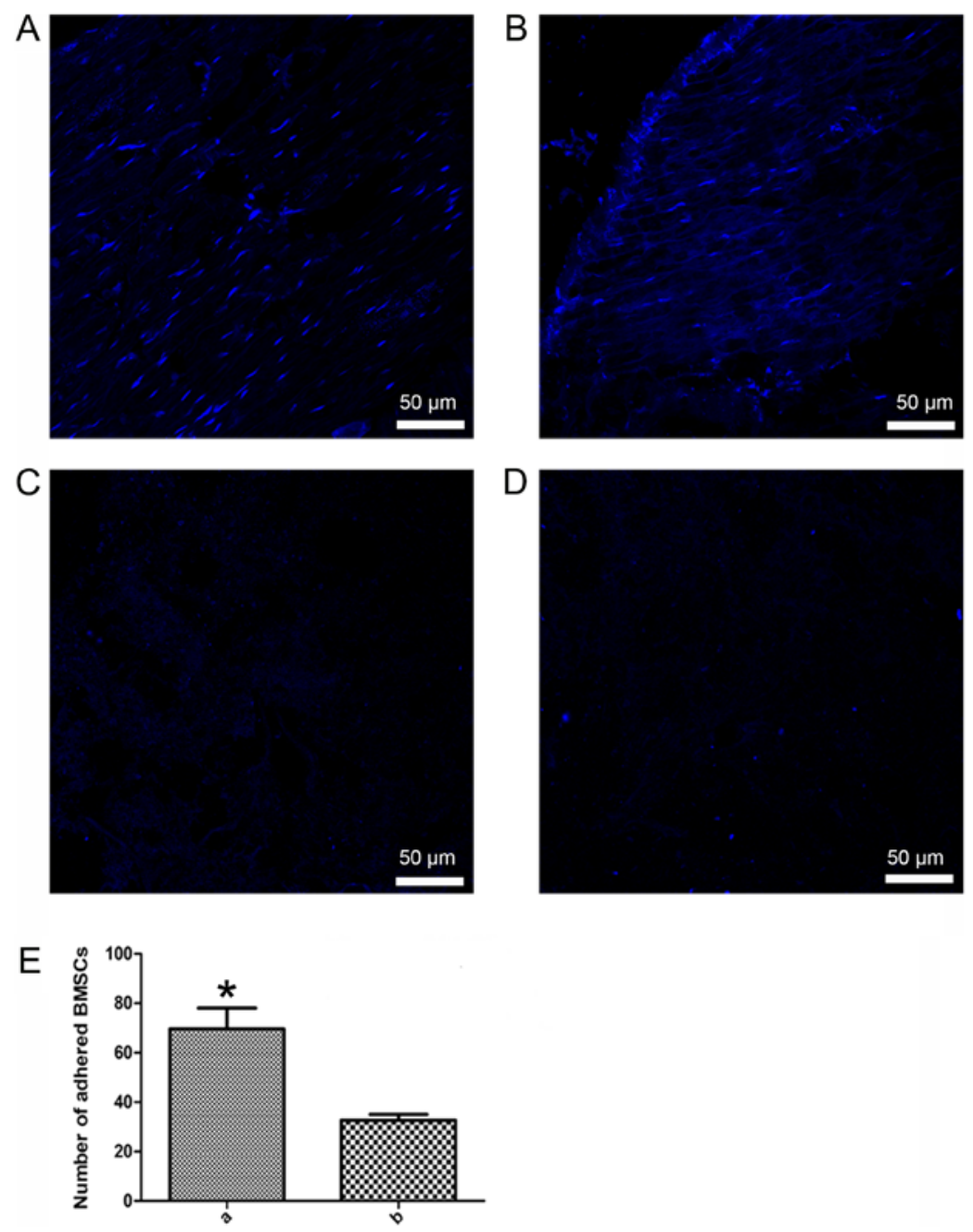

Figure 8. BMSC adhesion in the two groups. (A) Improved, (B) traditional, (C) control (for improved scaffolds) and (D) control (for traditional scaffolds) groups. (E) BMSC adhesion; a, improved group; b, traditional group. "P<0.05 compared with group b. BMSC, bone marrow mesenchymal stem cell.

After additional supplementation with growth factors, MSCs were differentiated into neuron-like cells on the scaffolds (Fig. 9A and B). The improved scaffolds (Fig. 9A) were more favorable for BMSC growth and differentiation than the traditional scaffolds (Fig. 9B), as verified using an NF-200 antibody. Additionally, NF-200-positive expression was increased in the improved group compared with in the traditional group (Fig. 9C).

Gene expression in differentiated BMSCs. RT-qPCR was used to determine neuronal gene expression in differentiated MSCs in the traditional and improved groups. MSCs were seeded into scaffolds and cultured in neural induction medium for 7 days. Subsequently, a key neuronal cell marker was detected, Nefh. Nefh expression was increased in the improved group compared with in the traditional group (Fig. 10).

\section{Discussion}

In spinal tissue engineering studies there are three basic elements, including seed cells, scaffolds and tissue factors (18). Tissue engineering scaffolds include a wide variety of materials, and acellular matrix scaffolds have demonstrated great potential in animal studies $(1,19)$. A recent preliminary study attempted to ascertain the potential of acellular matrix scaffolds in central nervous system repair (9). Guo et al (10) successfully prepared an acellular spinal cord scaffold using a chemical extraction method, and confirmed the excellent characteristics of the scaffold. In addition, Jiang et al (11) used genipin to crosslink the scaffold to improve its mechanical properties and increase cell adhesion to the scaffold. Previous studies have suggested that acellular spinal cord scaffolds combined with BMSCs can promote axonal regeneration and functional recovery in a spinal cord injury model $(20,21)$. In the present study, EDC crosslinking combined with chemical extraction was used to prepare acellular spinal cord scaffolds in the improved group; this led to improved immunogenicity, as indicated by reduced infiltration, and higher efficiency. Furthermore, the improved group exhibited complete decellularization, as detected by H\&E and DAPI staining, and reduced DNA content. BMSCs have the potential to proliferate and differentiate into osteogenic, chondrogenic, adipogenic and neural cell lines $(13,14,22)$. In this study, MSCs were cultivated in acellular spinal cord scaffolds and the following trophic factors were added to induce adhesion and proliferation: $10 \mathrm{ng} / \mathrm{ml} \mathrm{NT-3,} 10 \mathrm{ng} / \mathrm{ml} \mathrm{bFGF}$ and $10 \mathrm{ng} / \mathrm{ml}$ EGF. Immunofluorescence and RT-qPCR verified that improved 

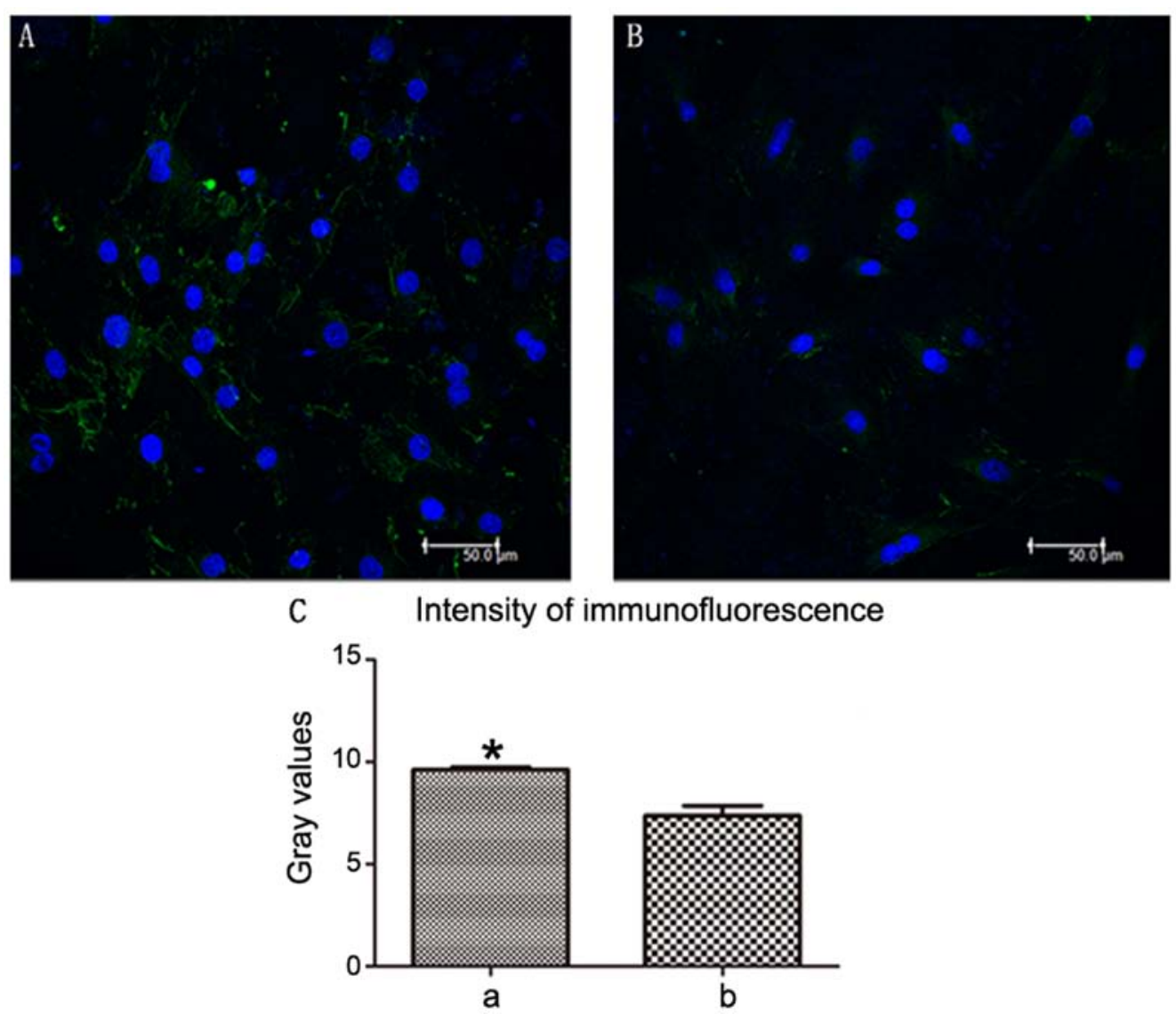

Figure 9. BMSC differentiation in the two groups. (A) Improved group and (B) traditional group. (C) Intensity of Nefh immunofluorescence, which indicated BMSC differentiation. a, improved group; $b$, traditional group. Data are presented as the mean \pm standard deviation, $n=3$. $P<0.05$ compared with group $b, t-t e s t$. BMSC, bone marrow mesenchymal stem cell. Blue, DAPI; green, Nefh. Nefh, neurofilament heavy.

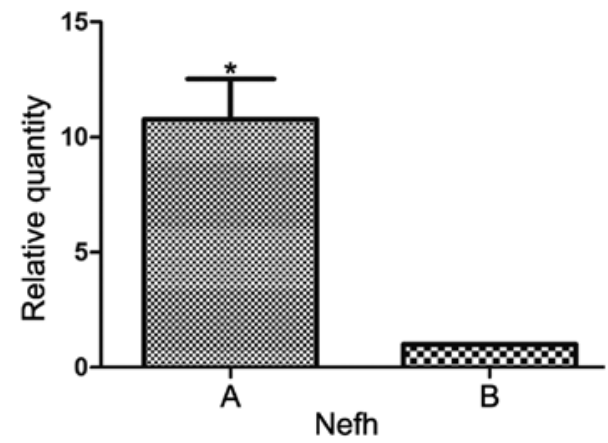

Figure 10. Nefh gene expression in differentiated BMSCs in the two groups. A, Improved group; B, traditional group. Data are presented as the mean \pm standard deviation, $\mathrm{n}=3$. ${ }^{*} \mathrm{P}<0.05$ compared with $\mathrm{B}$ group, $\mathrm{t}$-test. Nefh, neurofilament heavy.

group scaffolds promoted MSC adhesion, proliferation and differentiation into neurons/neuron-like cells.

Chemical extraction and enzymatic methods are common decellularization techniques $(6,23,24)$. However, the result of chemical extraction is often unstable, and enzymatic approaches often excessively damage the tissue components (25). The white matter of spinal cord tissue contains few cells, whereas the central gray matter contains more cells. With traditional decellularization methods, the central gray matter cells can never be completely cleared; however, with improved methods, namely
EDC crosslinking and chemical extraction, cells in both the white and grey matter can be thoroughly removed. EDC/NHS is an effective protein crosslinking agent (26). Previous studies have reported that EDC crosslinking can increase the stability and stiffness of scaffolds, to the point where they can resist destruction by chemical extraction (16,27-30). Preparation of the improved group scaffolds involved crosslinking by EDC, which may increase the stability of scaffolds, allowing them to pass through the next round of freeze-thawing and chemical extraction intact.

BMSCs have the potential to differentiate into multiple lineages. See et al (22) reported that MSCs cultured on natural collagen scaffolds maintain the potential for multiple differentiation. Previous studies demonstrated that BMSCs, administered via the cerebrospinal fluid or intravenously, migrate to the injured spinal cord, with the highest concentration at the lesion center. Immunostaining of nestin indicated that BMSCs may differentiate into neural cells, mature neurons or glial cells $(30,31)$. As BMSCs are useful for spinal cord recovery after injury, they were selected as the seed cells in the present study. NT-3 can specifically act on acute brain injury and helps maintain neuron survival and promotes the repair of injured nerves (32). NT-3, in combination with bFGF and EGF, can promote MSC differentiation into neuron-like cells (14). Therefore, these three factors were selected to treat BMSCs seeded onto acellular spinal cord scaffolds, in order to meet the requirements for spinal cord tissue engineering. 
EDC crosslinking was used to prepare the improved scaffolds in this study. Haugh et al (33) reported that collagen-glycosaminoglycan scaffolds crosslinked by EDC exhibit improved cell attachment, proliferation and infiltration. Previous studies have also made similar conclusions; that crosslinked scaffolds are conducive to seed cell adhesion and proliferation $(34,35)$. These findings suggested that the improved scaffolds may have potential in tissue engineering. Under stimulation by NT-3, bFGF and EGF, BMSCs can differentiate into neuron-like cells. This study used immunohistochemistry and RT-qPCR to examine the expression levels of neuronal differentiation-specific proteins and genes.

Immunohistochemistry was used to examine the differentiation of MSCs into neuron-like cells. The neuron marker NF-200 was used to detect differentiated neuron-like cells. As determined using immunohistochemistry or RT-qPCR, the improved group scaffolds out-performed the traditional group, promoting the differentiation of MSCs into neuron-like cells. These findings may be due to the improved group stents being crosslinked by EDC, increasing toughness that may be associated with mechanical properties. Banks et al (16) reported that EDC crosslinking increases the mechanical properties of collagen scaffolds and promotes the differentiation of adipose-derived MSCs into osteoblasts without the need for additional growth factors. Crosslinked scaffolds were also shown to facilitate seed cell differentiation. Therefore, EDC crosslinking may increase the mechanical properties of improved scaffolds; however, this study did not measure the mechanical properties of the traditional and improved scaffolds. PCR demonstrated a marked difference in the expression levels of Nefh, indicating that, under stimulation by NT-3, bFGF and EGF, and during the process of BMSC differentiation into neuron-like cells, Nefh mRNA may be sensitive to alterations in cell differentiation. It was suggested that Nefh mRNA may be sensitive enough to measure BMSC differentiation into neuron-like cells. The innovation of this study lies in the addition of NT-3, bFGF and EGF to BMSCs, combined with improved decellularized spinal cord scaffolds, and in demonstrating that the improved group was conducive to the differentiation of BMSCs into neuron-like cells. To the best of our knowledge, this study provided a novel approach to the construction of scaffolds for spinal cord tissue engineering.

The present study had some limitations. The first limitation involved the addition of trophic factors to promote BMSC differentiation: Neurotrophic factors often lose their protein activity at $\sim 37^{\circ} \mathrm{C}$, so they need to be supplemented over time. Another limitation was as follows: MSCs were differentiated into neuron-like cells; however, although the general morphology of the cells was consistent with neurons, and the differentiated neuron-like cells were positive for NF-200 immunofluorescence, only one neuronal protein marker was detected. In subsequent experiments, numerous neuronal marker antibodies should be used to verify MSC differentiation into neuronal cells.

To the best of our knowledge, this is the first study to improve the preparation efficiency of acellular spinal cord scaffolds. The results confirmed that EDC crosslinking combined with chemical extraction methods may effectively improve the efficiency of decellularization. After supplementing with specific neurotrophic factors, BMSCs adhered to the acellular spinal cord scaffolds, and were able to grow and differentiate into neuron-like cells. Compared with the traditional group, the improved group stents promoted the adhesion and differentiation of BMSCs, and the improved group scaffold may have great potential for spinal cord tissue engineering.

\section{Acknowledgements}

Not applicable.

\section{Funding}

The present study was supported by the National Youth Science Foundation (grant no. 31000438) and the National Natural Science Foundation of China (grant no. 81271362).

\section{Availability of data and materials}

The datasets used and/or analyzed during the present study are available from the corresponding author on reasonable request.

\section{Authors' contributions}

TJ conceived and designed the experiments. HX, HY, CS, YT and MY performed the experiments. HX, HY and XR analyzed the data. XR and TJ contributed reagents and materials. HX, $\mathrm{XR}$ and TJ wrote the paper and translated it into English.

\section{Ethics approval and consent to participate}

The present study was conducted in accordance with the Declaration of Helsinki and the National Institutes of Health Guide for the Care and Use of Laboratory Animals. All experimental protocols were approved by the Review Committee for the Use of Animal Subjects of the Army Medical University (animal production license number: SCXK-PLA-20120011; animal handling license number: SYXK-PLA-20120031).

\section{Patient consent for publication}

Not applicable.

\section{Competing interests}

The authors declare that they have no competing interests.

\section{References}

1. Baiguera S, Jungebluth P, Burns A, Mavilia C, Haag J, De Coppi P and Macchiarini P: Tissue engineered human tracheas for in vivo implantation. Biomaterials 31: 8931-8938, 2010.

2. Chen RN, Ho HO, Tsai YT and Sheu MT: Process development of an acellular dermal matrix (ADM) for biomedical applications. Biomaterials 25: 2679-2686, 2004.

3. Ji R, Zhang N, You N, Li Q, Liu W, Jiang N, Liu J, Zhang H, Wang D, Tao K and Dou K: The differentiation of MSCs into functional hepatocyte-like cells in a liver biomatrix scaffold and their transplantation into liver-fibrotic mice. Biomaterials 35: 8995-9008.

4. Woods T and Gratzer PF: Effectiveness of three extraction techniques in the development of a decellularized bone-anterior cruciate ligament-bone graft. Biomaterials 36: 7339-7349, 2005.

5. Sánchez PL, Fernández-Santos ME, Costanza S, Climent AM, Moscoso I, Gonzalez-Nicolas MA, Sanz-Ruiz R, Rodríguez H, Kren SM, Garrido G, et el: Acellular human heart matrix: A critical step toward whole heart grafts. Biomaterials 61: 279-289, 2015. 
6. Laronda MM, Jakus AE, Whelan KA, Wertheim JA, Shah RN and Woodruff TK: Initiation of puberty in mice following decellularized ovary transplant. Biomaterials 50: 20-29, 2015.

7. Ravindran S, Kotecha M, Huang C, Ye A, Pothirajan P, Yin Z, Magin R and George A: Biological and MRI characterization of biomimetic ECM scaffolds for cartilage tissue regeneration. Biomaterials 78: 58-70, 2015.

8. Cai M, Huang T, Hou B and Guo Y: Role of demyelination efficiency within acellular nerve scaffolds during nerve regeneration across peripheral defects. Biomed Res Int 2017: 4606387, 2017.

9. Crapo PM, Medberry CJ, Reing JE, Tottey S, van der Merwe Y, Jones KE and Badylak SF: Biologic scaffolds composed of central nervous system. Biomaterials 33: 3539-3547, 2012.

10. Guo SZ, Ren XJ, Wu B and Jiang T: Preparation of the acellular scaffold of the spinal cord and the study of biocompatibility. Spinal Cord 48: 576-581, 2010

11. Jiang T, Ren XJ, Tang JL, Yin H, Wang KJ and Zhou CL: Preparation and characterization of genipin-crosslinked rat acellular spinal cord scaffolds. Mater Sci Eng C Mater Biol Appl 33: 3514-3521, 2013.

12. Wang L, Wang ZH, Shen CY, You ML, Xiao JF and Chen GO Differentiation of human bone marrow mesenchymal stem cells grown in terpolyesters of 3-hydroxyalkanoates scaffolds into nerve cells. Biomaterials 31: 1691-1698, 2010.

13. Zhang K, Liu Z, Li G, Lai BQ, Qin LN, Ding Y, Ruan JW, Zhang SX and Zeng YS: Electro-acupuncture promotes the survival and differentiation of transplanted bone marrow mesenchymal stem cells pre-induced with neurotrophin-3 and retinoic acid in gelatin sponge scaffold after rat spinal cord transection. Stem Cell Rev 10: 612-625, 2014.

14. Guan M, Xu Y, Wang W and Lin S: Differentiation into neurons of rat bone marrow-derived mesenchymal stem cells. Eur Cytokine Netw 25: 58-63, 2014

15. Parekkadan B and Milwid JM: Mesenchymal stem cells as therapeutics. Annu Rev Biomed Eng 12: 87-117, 2010.

16. Banks JM, Mozdzen LC, Harley BA and Bailey RC: The combined effects of matrix stiffness and growth factor immobilization on the bioactivity and differentiation capabilities of adipose-derived stem cells. Biomaterials 35: 8951-8959. 2014.

17. Livak KJ and Schmittgen TD: Analysis of relative gene expression data using real-time quantitative PCR and the 2(-Delta Delta C(T)) method. Methods 25: 402-408, 2001.

18. Dado D and Levenberg S: Cell-scaffold mechanical interplay within engineered tissue. Semin Cell Deve Biol 20: 656-664, 2009.

19. Kehoe S, Zhang XF and Boyd D: FDA approved guidance conduits and wraps for peripheral nerve injury: A review of materials and efficacy. Injury 45: 553-572, 2012.

20. Liu J, Chen J, Liu B, Yang C, Xie D, Zheng X, Xu S, Chen T, Wang L, Zhang Z, et al: Acellular spinal cord scaffold seeded with mesenchymal stem cells promotes long-distance axon regeneration and functional recovery in spinal cord injured rats. J Neurol Sci 325: 127-136, 2013.

21. Chen J, Zhang Z, Liu J, Zhou R, Zheng X, Chen T, Wang L, Huang M, Yang C, Li Z, et al: Acellular spinal cord scaffold seeded with bone marrow stromal cells protects tissue and promotes functional recovery in spinal cord-injured rats. J Neurosci Res 92: 307-317, 2014.
22. See EY, Toh SL and Goh JC: Multilineage potential of bone-marrow-derived mesenchymal stem cell cell sheets: Implications for tissue engineering. Tissue Eng Part A 16: 1421-1431, 2010

23. Ngangan AV and McDevitt TC: Acellularization of embryoid bodies via physical disruption methods. Biomaterials 30: 1143-1149, 2009.

24. Burk J, Erbe I, Berner D, Kacza J, Kasper C, Pfeiffer B, Winter K and Brehm W: Freeze-thaw cycles enhance decellularization of large tendons. Tissue Eng Part C Methods 20: 276-284, 2014.

25. Grauss RW, Hazekamp MG, Oppenhuizen F, van Munsteren CJ, Gittenberger-de Groot AC and DeRuiter MC: Histological evaluation of decellularised porcine aortic valves: Matrix changes due to different decellularisation methods. Eur J CardioThoracic Surg 27: 566-571, 2005.

26. Huang GP, Shanmugasundaram S, Masih P, Pandya D, Amara S, Collins G and Arinzeh TL: An investigation of common crosslinking agents on the stability of electrospun collagen scaffolds. J Biomed Mater Res A 103: 762-771, 2015.

27. Kozowska J and Sionkowska A: Effects of different crosslinking methods on the properties of collagen-calcium phosphate composite materials. Int J Biol Macromol 74: 397-403, 2015.

28. Priyadarshani P, Li Y, Yang S and Yao L: Injectable hydrogel provides growth-permissive environment for human nucleus pulposus cells. J Biomed Mater Res A 104: 419-426, 2016.

29. Wang Y, Wang X, Shi J, Zhu R, Zhang J, Zhang Z, Ma D, Hou Y, Lin F, Yang J and Mizuno M: A biomimetic silk fibroin/sodium alginate composite scaffold for soft tissue engineering. Sci Rep 6: 39477, 2016.

30. Satake K, Lou J and Lenke LG: Migration of mesenchymal stem cells through cerebrospinal fluid into injured spinal cord tissue. Spine (Phila Pa 1976) 29: 1971-1979, 2004.

31. Khalatbary AR and Tiraihi T: Localization of bone marrow stromal cells in injured spinal cord treated by intravenous route depends on the hemorrhagic lesions in traumatized spinal tissues. Neurol Res 29: 21-26, 2007.

32. Liu T, Xu J, Chan BP and Chew SY: Sustained release of neurotrophin-3 and chondroitinase $\mathrm{ABC}$ from electrospun collagen nanofiber scaffold for spinal cord injury repair. J Biomed Mater Res A 100: 236-242, 2012.

33. Haugh MG, Murphy CM, McKiernan RC, Altenbuchner C and O'Brien FJ: Crosslinking and mechanical properties significantly influence cell attachment, proliferation, and migration within collagen glycosaminoglycan scaffolds. Tissue Eng Part A 17: 1201-1208, 2011.

34. Thitiset T, Damrongsakkul S, Bunaprasert T, Leeanansaksiri W and Honsawek S: Development of collagen/demineralized bone powder scaffolds and periosteum-derived cells for bone tissue engineering application. Int J Mol Sci 14: 2056-2071, 2013.

35. Liu C,McKennaFM,Liang H,Johnstone A and AbelEW:Enhanced cell colonization of collagen scaffold by ultraviolet/ozone surface processing. Tissue Eng Part C Methods 16: 1305-1314, 2010.

This work is licensed under a Creative Commons Attribution-NonCommercial-NoDerivatives 4.0 International (CC BY-NC-ND 4.0) License. 